\title{
Perception and Feelings of Antenatal Women during COVID-19 Pandemic: A Cross-Sectional Survey
}

Qiu Ju Ng, ${ }^{1}$ MBBS, MRCOG, MMed (O\&G), Krystal ML $\underline{\text { Koh }},{ }^{1}$ MBBS, Shephali Tagore, ${ }^{2}$ MBBS, MD (O\&G), FRCOG, Manisha Mathur, ${ }^{1}$ MBBS (India), FRCOG

\begin{abstract}
Introduction: To assess the level of anxiety and knowledge regarding COVID-19 amongst antenatal women. Materials and Methods: This cross-sectional survey was conducted in the antenatal clinics of KK Women's and Children's Hospital, Singapore, from 31 March to 25 April 2020 to assess pregnant women's knowledge of COVID-19, their perceptions of its impact upon pregnancy and psychological impact using the validated Depression, Anxiety, and Stress Scales (DASS-21). Results: Of the 324 women who participated in the study, the mean age was 31.8 years (range, $20-45)$. The majority $(53.7 \%)$ were multiparous with mean gestational age of 23.4 weeks (SD 10). The commonest sources of information were Internet-based social media platforms. A significant proportion were unaware, or associated COVID-19 infection during pregnancy with fetal distress $(82.1 \%)$, intrauterine death $(71.3 \%)$, fetal anomalies $(69.8 \%)$, miscarriages $(64.8 \%)$, preterm labour $(67.9 \%)$ and rupture of membranes (61.4\%). A total of $116(35.8 \%)$ women screened positive for anxiety, $59(18.2 \%)$ for depression, and $36(11.1 \%)$ for stress. There was a significant association between household size and stress scores $[B=0.0454(95 \% C I, 0.0035-0.0873)]$. Women who associated COVID-19 infection with fetal anomalies and intrauterine fetal death had significantly higher anxiety scores $[B=-0.395(95 \% \mathrm{CI},-0.660$ to -0.130$)$ and $B$ $=-0.291(95 \% \mathrm{CI},-\mathbf{0 . 5 6 2}$ to -0.021$)$ respectively]. Conclusion: Our study highlights that a lack of timely and reliable information on the impact of COVID-19 on pregnancy and its outcomes results in increased levels of depression, anxiety and stress. The healthcare provider must address these issues urgently by providing evidence-based information using Internet-based resources and psychological support.
\end{abstract}

Ann Acad Med Singap 2020;50:543-52

Key words: Depression, Anxiety, Stress, Pregnancy, Knowledge

\section{Introduction}

Severe acute respiratory syndrome coronavirus 2 (SARS-CoV-2), the causative agent of coronavirus disease 2019 (COVID-19), is a novel coronavirus from the same family as SARS. The SARS-CoV-2 virus, which originated in Wuhan, China in December 2019, was designated as a pandemic by the World Health Organization (WHO) on 11 March 2020. ${ }^{1,2}$ Singapore had previously experienced outbreaks of SARS in 2003, and H1N1 in 2009. ${ }^{3}$ Singapore is a densely populated country with a population of 5.7 million, and the number of cases has been rising exponentially since mid April 2020. As of 25 August 2020, there has been a total of 56,435 cases with 1,592 active cases and 27 deaths. $^{4}$

The impact of COVID-19 upon pregnancy is poorly understood. Pregnancy does not seem to increase the likelihood of contracting COVID-19 infection; however, there is a theoretical increased risk of complications due to the altered physiology and immunity of patients. ${ }^{5-7}$ Currently, there are limited reports regarding the impact of COVID-19 infection on pregnancy and the foetus. Vertical transmission has been deemed possible due to recent findings of elevated COVID-19 immunoglobulin

\footnotetext{
${ }^{1}$ Department of Obstetrics and Gynecology, KK Women's and Children's Hospital, Singapore, Singapore

${ }^{2}$ Department of Maternal and Fetal Medicine, KK Women's and Children's Hospital, Singapore

Address for Correspondence: Dr Ng Qiu Ju, KK Women's and Children's Hospital, 100 Bukit Timah Road, Singapore 229899.

Email: qiuju89@gmail.com
} 
M levels in neonates born to infected mothers, although earlier reports did not suggest it. ${ }^{5-12}$

Due to the paucity of data about COVID-19 infection during pregnancy, information from other viruses may provide some insight into its effects. The SARS outbreak in 2003 and H1N1 in 2009 reported adverse pregnancy outcomes ranging from pneumonia to death. ${ }^{13-16}$ These reports, and the development of the current pandemic, have resulted in worry and anxiety among those pregnant.

Studies are emerging on the psychological impact of COVID-19 on the general population and healthcare professionals, ${ }^{18-22}$ but there is a lack of similar studies in pregnant women.

Our study aims to look at the baseline knowledge regarding COVID-19, and assess the level of anxiety, depression and stress in the obstetric population in a tertiary referral centre in Singapore.

\section{Materials and Methods}

This cross-sectional survey was conducted in the antenatal clinics of KK Women's and Children's Hospital, which is the largest tertiary maternity unit in Singapore. From 31 March to 25 April 2020, healthy pregnant women attending the clinics were randomly invited to participate in the study by answering an anonymous questionnaire. As this was an anonymous survey-based cross-sectional study, it was exempted from Institutional Review Board approval.

The survey aimed to assess pregnant women's' knowledge of COVID-19 infection, their perceptions of its impact upon their pregnancy and the psychological impact of COVID-19 pandemic, by using the validated Depression, Anxiety, and Stress Scales (DASS-21).

The structured questionnaire consisted of 4 sections. The first section included demographic data. The next section focused on sources of information and knowledge regarding COVID-19 transmission. The third section assessed women's knowledge regarding COVID-19 and its implications on pregnancy, delivery and breastfeeding. The women rated their answers on a range from 1 to 5 , where 1 implied strong agreement and 5 strong disagreement. For data analysis, we grouped responses 1 and 2 as agreeing to the statement, and responses 3 to 5 as unsure or disagreeing with the statement.

The last section of the questionnaire assessed the psychological impact of COVID-19 using DASS-21, which screened for depression, anxiety and stress. ${ }^{23}$ A positive screen for depression was defined as a score of $>9$ points. A score of 10 to 13 was mild depression, 14 to 20 moderate depression, 21 to 27 severe depression, and a score of $>28$ was extreme severe depression. A positive screen for anxiety was defined as a score of $>7$ points. A score of 8 to 9 was taken as mild anxiety, 10 to 14 moderate anxiety, 15 to 19 severe anxiety, and a score of 20 and above was extreme severe anxiety. A positive screen for stress was defined as a score of $>14$ points. A score of 15 to 18 was mild stress, 19 to 25 moderate stress, 26 to 33 severe stress, and a score of 37 and above was extreme severe stress. DASS-21 was shown to be reliable and valid for use during the perinatal period for such a screening. ${ }^{24-25}$

\section{Statistical Analysis}

All statistical analyses were performed with $\mathrm{R}$ Statistical Software. The descriptive statistics were calculated for demographic characteristics, frequency of sources of information, and knowledge on COVID-19 infection. Univariate linear regressions were performed to assess the association between DASS scores and demographic characteristics, as well as knowledge about COVID-19. The significance level was set at a $P$ value of 0.05 .

\section{Results}

Of the 325 healthy pregnant women invited to participate in the study, $324(99.4 \%)$ agreed, while 1 woman declined due to her limited grasp of the English language.

\section{Demographics}

The mean age of the participating antenatal women was 31.8 years (range, 20-45) (Table 1). There were similar numbers of Chinese and Indian women (34\%, $\mathrm{n}=110$ and $33 \%, \mathrm{n}=106$ respectively), followed by Malay women $(24 \%, \mathrm{n}=79)$, while other ethnicities contributed $9 \%(n=29)$. Singaporean citizens constituted the majority $(61.4 \%, \mathrm{n}=199)$ of the cohort, followed by permanent residents $(17 \%, \mathrm{n}=55)$, and the rest were foreigners $(21.6 \%, \mathrm{n}=70)$. In our study population, $62.3 \%(\mathrm{n}=202)$ of the women had at least a university degree. Most $(78.1 \%, \mathrm{n}=253)$ women lived in Housing Development Boards (HDB) flats, which are public housing, while $21.3 \%(n=69)$ resided in condominiums or landed properties. The mean household size of the cohort was 3.7 (range, 1-8), with the majority having $>1$ child at home.

All except 2 of the pregnancies were singleton pregnancies; the remaining being dichorionic diamniotic (DCDA) pregnancies. A majority of the women $(53.7 \%, \mathrm{n}=174)$ were multiparous. The mean gestational 
Table 1. Characteristics of the Cohort

\begin{tabular}{|c|c|c|}
\hline \multicolumn{2}{|l|}{ Characteristics } & \multirow[b]{2}{*}{$31.8(4.2)$} \\
\hline Age, mean (SD), years & & \\
\hline \multirow[t]{6}{*}{ Parity, no (\%) } & 0 & $150(46.3)$ \\
\hline & 1 & $124(38.3)$ \\
\hline & 2 & $34(10.5)$ \\
\hline & 3 & $11(3.4)$ \\
\hline & 4 & $4(1.2)$ \\
\hline & 5 & $1(0.3)$ \\
\hline \multirow[t]{4}{*}{ Race, no (\%) } & Chinese & $110(34)$ \\
\hline & Malay & $79(24)$ \\
\hline & Indian & $106(33)$ \\
\hline & Others & $29(9)$ \\
\hline Gestational age, mean (SD), weeks & & $23.4(10)$ \\
\hline Low risk pregnancies, no (\%) & & $253(78.1)$ \\
\hline \multirow[t]{3}{*}{ Citizenship, no (\%) } & Singapore citizens & $199(61.4)$ \\
\hline & Singapore permanent residents & $55(17)$ \\
\hline & Foreigners & $70(21.6)$ \\
\hline \multirow[t]{6}{*}{ Education level, no (\%) } & Primary/Secondary school & $12(4)$ \\
\hline & GCE N level/GCE O level/ ITE certificate & $39(12)$ \\
\hline & GCE A level certificate/Diploma & $71(22)$ \\
\hline & University degree & $141(44)$ \\
\hline & Masters degree & $58(18)$ \\
\hline & $\mathrm{PhD}$ degree & $3(1)$ \\
\hline \multirow[t]{3}{*}{ Marital status, no (\%) } & Married & $320(98.8)$ \\
\hline & Single & $3(0.9)$ \\
\hline & Divorced & $1(0.3)$ \\
\hline \multirow[t]{2}{*}{ Employment status, no (\%) } & Unemployed & $97(30)$ \\
\hline & Employed & $227(70)$ \\
\hline \multirow[t]{4}{*}{ Housing type, no (\%) } & Rental flat & $2(0.6)$ \\
\hline & HDB flat & $253(78.1)$ \\
\hline & Condominium & $65(20.1)$ \\
\hline & Landed property & $4(1.2)$ \\
\hline Household size, no (\%) & & $3.7(1.5)$ \\
\hline \multirow[t]{5}{*}{ Number of living children, no (\%) } & 1 & $123(46)$ \\
\hline & 2 & $33(38)$ \\
\hline & 3 & $13(4)$ \\
\hline & 4 & $4(1)$ \\
\hline & 5 & $2(1)$ \\
\hline
\end{tabular}

GCE: General Certificate of Education; HDB: Housing Development Board; ITE: Institute of Technical Education 
age was 23.4 weeks (range, 4.4-39.4 weeks). Most of the women $(78.1 \%, \mathrm{n}=253)$ had low-risk pregnancies. Of the remaining, 6 were in-vitro fertilisation pregnancies, 9 had a diagnosis of pre-existing diabetes or gestational diabetes, and 8 had fetal issues ranging from intrauterine growth restriction to fetal anomalies.

\section{Sources of Information}

The most common sources used by antenatal women for obtaining information regarding COVID-19 infection and its effects were social media platforms, constituting Facebook and WhatsApp message forwards (Table 2). To provide up-to-date but basic information, the Singaporean Government started an initiative for residents to sign up to receive updates via text messages daily. ${ }^{26}$ The other sources used, ranked in terms of frequency of use were Internet-based search engines, newspapers or leaflets, family and friends, their doctors, and others such as television. Interestingly, only $14 \%(n=45)$ of them received information regarding COVID-19 from their doctors. All except 1 woman knew that transmission of COVID-19 could occur directly or indirectly via contact of contaminated surfaces.

The participants rated their satisfaction level regarding the level of information provided on COVID-19 infection during pregnancy on a scale of 1 to 5 , where a rating of 1 was extremely unsatisfied and a rating of 5 was extremely satisfied. The median score for this question was 3 (SD 0.92). Of note, $42.9 \%(\mathrm{n}=139)$ were satisfied with the information provided, $43.5 \%(\mathrm{n}=141)$ were neutral, while $13.6 \%(n=44)$ were not satisfied.

\section{Knowledge regarding the Impact of COVID-19 Infections} on Pregnancy

It was interesting to note that $77.5 \%(\mathrm{n}=251)$ of women felt that pregnant women were more likely to get COVID-19 infection, while $42.6 \%(n=138)$ women thought that pregnant women would have a severe illness if they were infected. The majority of women $(83.0 \%, \mathrm{n}=269)$ believed that COVID-19 would pass onto the baby in the antenatal period. Many women were either unaware of risks of acquiring COVID-19 during pregnancy or believed that COVID-19 would cause fetal distress $(82.1 \%)$, intrauterine death $(71.3 \%)$, fetal anomalies (69.8\%), miscarriages $(64.8 \%)$, preterm labour $(67.9 \%)$ and rupture of membranes $(61.4 \%)$. A majority of the study participants $(66.7 \%, \mathrm{n}=216)$ were either unsure of their options with regards to the mode of delivery, or would request for a caesarean section if they were infected with COVID-19. Regarding the safety of breastfeeding for COVID-19 mothers, $74.7 \%$ $(\mathrm{n}=242)$ associated breastfeeding with an increased risk of transmission of infection to their newborns.

\section{DASS-21 Scores}

In our study, $35.8 \%(\mathrm{n}=116)$ antenatal women screened positive for anxiety, $18.2 \%(\mathrm{n}=59)$ screened positive for depression, and $11.1 \%(n=36)$ screened positive for stress. Among those screened positive for depression, $45.8 \%(\mathrm{n}=27)$ screened positive for mild depression, $45.8 \%(\mathrm{n}=27)$ for moderate depression, $5.1 \%(\mathrm{n}=3)$ for severe depression, and 3.4\% $(\mathrm{n}=2)$ for extreme severe depression. Among those screened positive for anxiety, $26.7 \%(\mathrm{n}=31)$ had mild anxiety, $53.4 \%(\mathrm{n}=62)$ had moderate anxiety, $7.8 \%(\mathrm{n}=9)$ had severe anxiety, and $12.1 \%(\mathrm{n}=14)$ had extremely severe anxiety. Among those screened positive for stress, $41.7 \%(n=15)$ had mild stress, $44.4 \%$ $(\mathrm{n}=16)$ had moderate stress, and 13.9\% $(\mathrm{n}=5)$ had severe stress.

Table 3 shows the associations between DASS-21 scores and the demographics of the study group. Table

Table 2. Sources of Information

\begin{tabular}{lr}
\hline Source & Number of Study Participants (\%) \\
\hline Internet- search engines & $179(55)$ \\
\hline Doctors & $45(14)$ \\
\hline Family/friends & $85(26)$ \\
\hline Leaflets/newspapers & $104(32)$ \\
\hline Social media (WhatsApp, Facebook, Gov.sg text messages) & $209(66)$ \\
\hline Others e.g., television & $15(5)$ \\
\hline
\end{tabular}




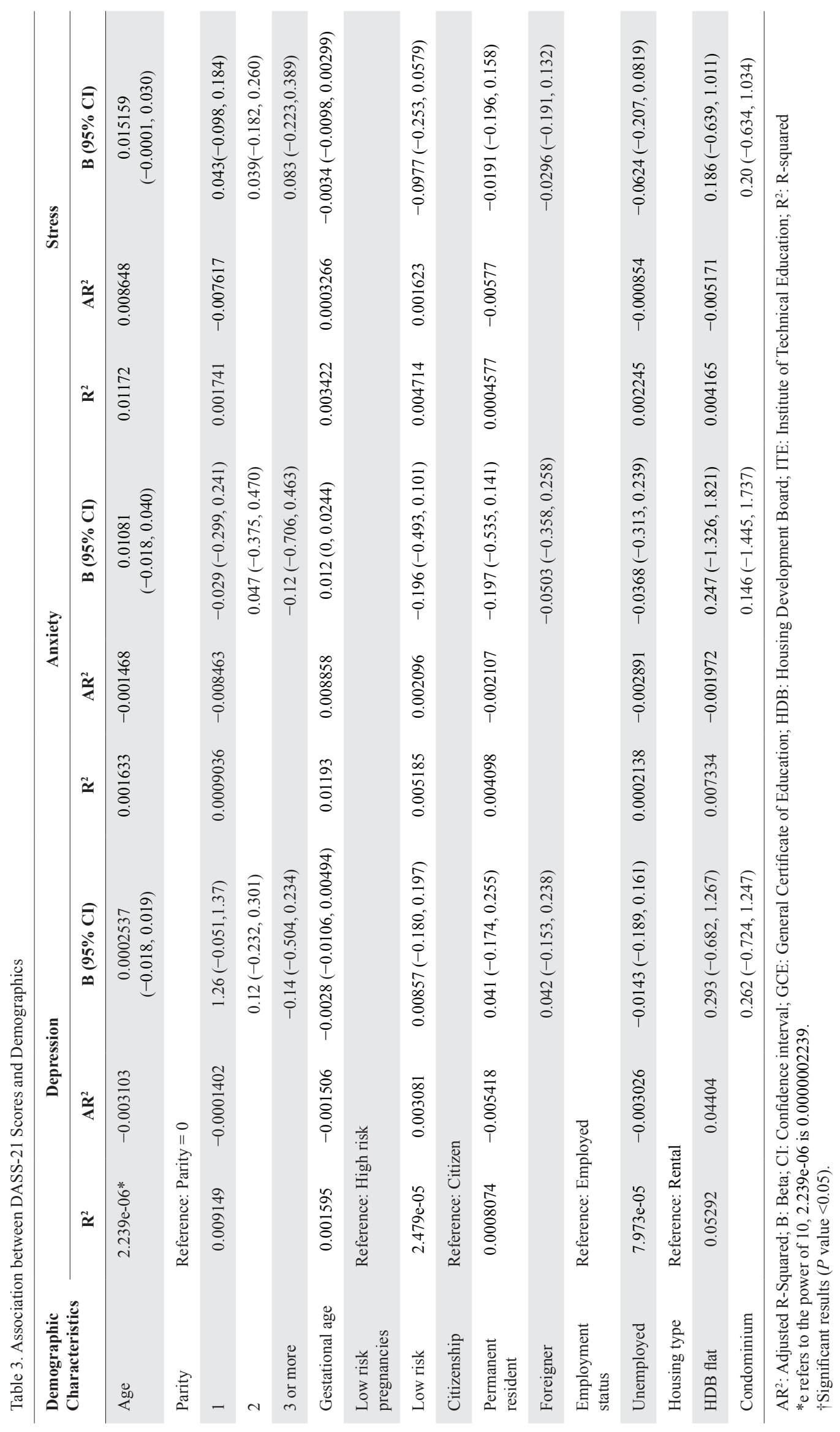




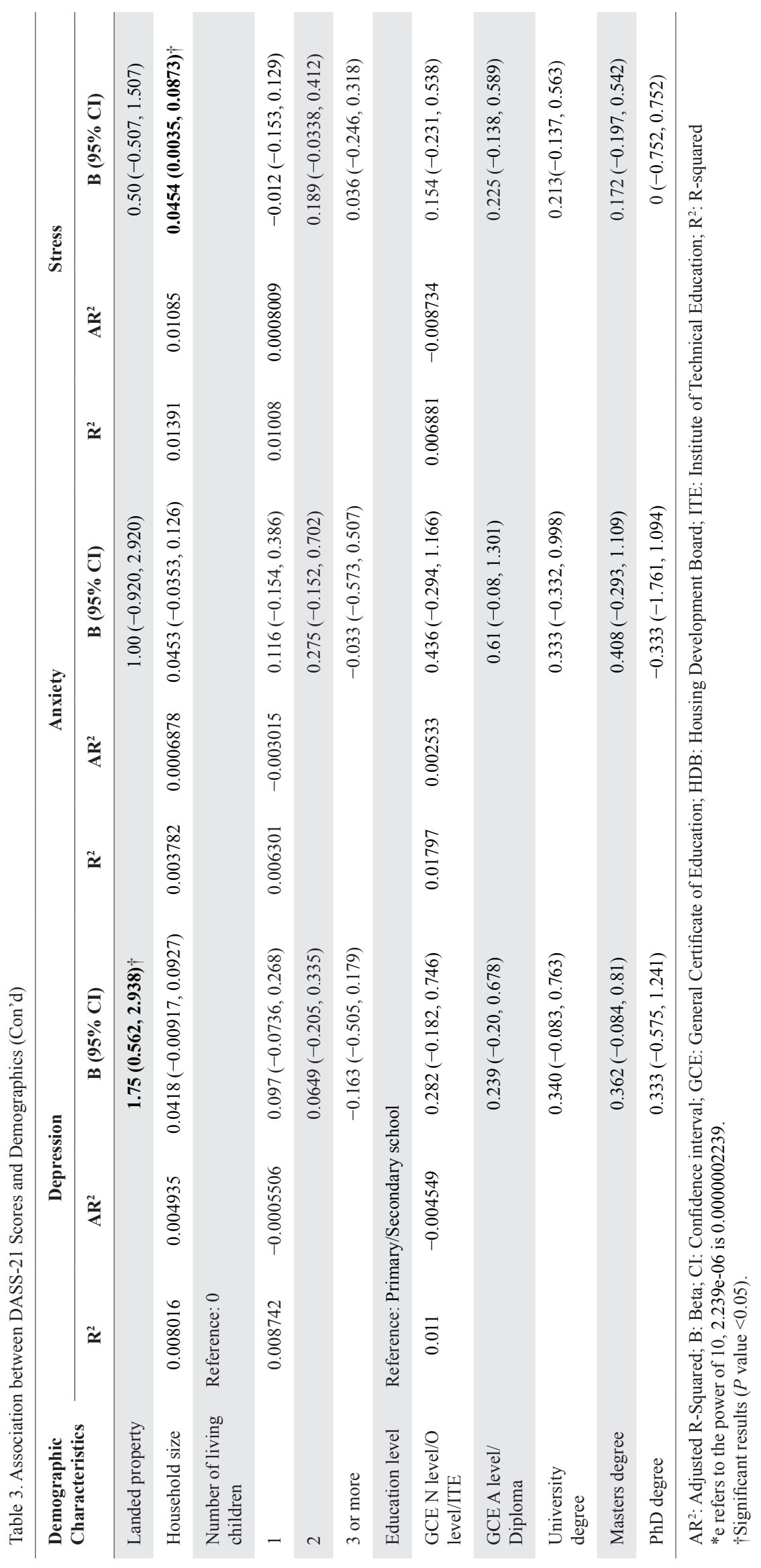


4 shows the associations between DASS-21 scores and their perceived knowledge of the impact of COVID-19 infection upon their pregnancy.

Living in a landed property was significantly associated with higher depression scores $[\mathrm{B}=1.75(95 \%$ CI, 0.562-2.938)]. A larger household size was significantly associated with higher stress scores $[\mathrm{B}=0.0454(95 \% \mathrm{CI}, 0.0035-0.0873)]$. There were no statistically significant associations with the rest of the demographics.

Women who believed that COVID-19 infection would be passed on to their babies antenatally or would cause fetal anomalies had significantly higher anxiety scores $[\mathrm{B}=-0.376,95 \% \mathrm{CI},-0.704$ to -0.0490 and $\mathrm{B}=-0.395(95 \% \mathrm{CI},-0.660$ to -0.130$)$ respectively]. Women who thought that COVID-19 would cause intrauterine death also had significantly higher anxiety scores $[\mathrm{B}=-0.291(95 \% \mathrm{CI},-0.562$ to -0.021$)]$.

Subgroup analysis showed that there were significant correlations between the education level, type of housing and women who believed that COVID-19 could cause intrauterine death. There were no significant associations between education levels and women who felt that COVID-19 could pass onto their babies during the antenatal period or could cause fetal anomalies.

\section{Discussion}

Since the WHO declaration of COVID-19 disease as a pandemic, the spread of the virus has been rapid. ${ }^{4}$ There has been widespread coverage of the pandemic details, including the morbidity and mortality statistics by all forms of media, leading to possible information overload and anxiety amongst the population. A recent Lancet publication reviewed the psychological impact of prior epidemics and reported adverse psychological effects. ${ }^{17}$ Another study highlighted that fear is a common occurrence for people exposed to infectious diseases and could be exacerbated by inadequate information. ${ }^{27}$ Although there is ongoing research to understand the disease evolution and its severity, our understanding of the disease remains limited, especially in the context of its effect upon pregnancy.

With the limited availability of validated information and given the history of prior viral epidemics affecting pregnant women with adverse outcomes, it is not surprising to expect adverse psychological impacts of COVID-19 pandemic amongst antenatal women.

Our study population consisted of young antenatal low-risk women. A majority of them had at least a university degree, indicating high educational attainment amongst this group. Almost all of these women resided in self-owned, public housing or high-end condominium apartments and landed properties, suggesting high socio-economic status.

More than half of them were not satisfied or neutral $(57.1 \%, \mathrm{n}=185)$ with the current level of their knowledge related to COVID-19 and its effect on the pregnancy. A significant proportion of the antenatal women were either unaware of the effects of COVID-19 or associated COVID-19 infection during pregnancy with adverse pregnancy outcomes and expressed that they would consider a delivery by a caesarean section if infected with COVID-19. Based on current literature, , $^{5-12}$ pregnant women do not appear to be more likely to be infected with COVID-19, although more severe symptoms may present in the third trimester as a result of physiological changes during pregnancy. There is some suggestion of vertical transmission of COVID-19, but the virus is not shown to be associated with teratogenicity and adverse outcomes such as miscarriage, intrauterine fetal growth restriction or preterm labour. Further studies have to be conducted in these areas. Although there is no contraindication to vaginal delivery, we have to individualise intrapartum management and the mode of delivery, depending upon the severity of the illness. Breastfeeding is encouraged if the woman is well and safe to do so, depending on local protocols. Precautions should be taken to reduce the risk of transmission during breastfeeding. These discrepancies in the women's views could be explained by the unprecedented spread of the disease worldwide, women's perceptions based on prior epidemics and also a lack of provision of timely information by healthcare providers.

The primary source used for acquiring information by these women was the various social media platforms. Interestingly, only $14 \%$ of the women obtained information from their doctors. A possible explanation could be that during the 2 to 4 -week interval between their antenatal appointments, women had used easily accessible alternate sources of information. A recent unpublished survey at our unit conducted on randomly selected antenatal women found that $100 \%$ of them owned a smartphone and used it for gaining information. Our study highlights the lack of accurate and updated information on the effects of COVID-19 on pregnancy among our local antenatal population. In light of these findings and with the widespread usage of mobile phones and Internet-based platforms, we recommend utilisation of hospital-based social media resources, such as hospital Facebook page and website, and App-based resources for providing timely evidence-based information to alleviate stress 


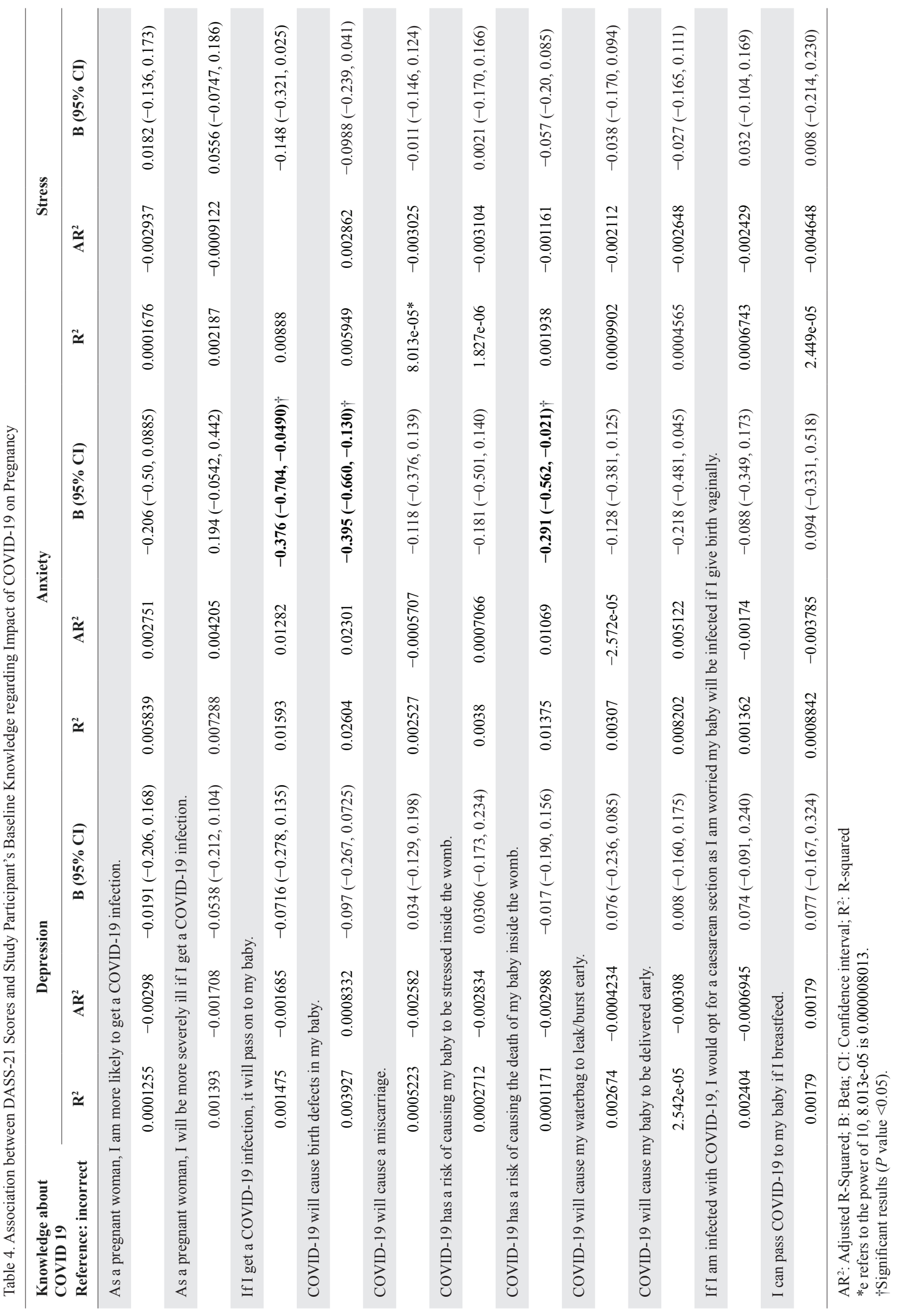


and anxiety amongst antenatal women, and as a more efficient means of communication. Healthcare providers should also consider providing links to this information by text messages for ease of use and accessibility. This strategy would help tailor information to be better suited to the needs of the stakeholders.

During a health crisis, the healthcare providers often prioritise on developing evidence-based protocols, screening and managing those infected. Hence, the provision of information to patients and their mental well-being may not be the primary focus. A significant number of our women screened positive for depression, anxiety and stress using the DASS-21 instrument. A smaller number of women in our study experienced severe depression, anxiety and stress. Chua et al had conducted a local cohort study which found that the prevalence of anxiety among low-risk antenatal women was $17.0 \%$, based on the Spielberger State-Trait Anxiety Inventory tool. ${ }^{28}$ The higher proportion of pregnant women in our study that screened positive for depression, anxiety and stress could be attributed to the COVID-19 pandemic. There was a lack of validated information from healthcare professionals for reasons as discussed and most of them turned to social media as a source of information. Hence, healthcare professionals must concurrently monitor the mental well-being of antenatal women so they may identify those who need help and intervene early.

$\mathrm{Wu}$ et al studied perinatal depression and its risk factors amongst pregnant women during the COVID-19 outbreak in China, using the Edinburgh Post Natal Depression Scale and concluded that the women were at a higher risk of mental illnesses. ${ }^{8}$ Our study presents a comprehensive understanding of the mental health problems during a pandemic by assessing stress, anxiety and depression using the DASS-21.

\section{Strengths and Limitations}

To the best of our knowledge, there has been no published studies available in the literature assessing baseline knowledge, sources of information, depression, anxiety, and stress levels during the antenatal period using DASS-21. Our study collected responses from a range of demographics, across races, citizenship status and socio-economic status, using a validated scale. As this was a random sample of obstetric patients attending the antenatal clinics in our centre, it may not fully represent the racial proportions of Singapore.
Another limitation of our study is that we did not have the baseline depression and stress scores of our antenatal population for comparison.

\section{Conclusion}

Our study highlights that a lack of timely and reliable information on the impact of COVID-19 on pregnancy and its outcomes leads to knowledge gaps in antenatal women, with a significant proportion of women reporting increased levels of anxiety and stressrelated symptoms. It also recognised that Internet-based platforms formed the primary sources for acquiring information. In a global health crisis, healthcare professionals need to address these issues urgently by giving evidence-based information promptly, using resources tailored to the needs of antenatal women. Assessment of mental health being should occur concurrently and early intervention in the form of psychological support should be provided to those who need it, to limit any long term impact on mental well-being.

\section{REFERENCES}

1. World Health Organization. WHO Director-General's opening remarks at the media briefing on COVID-19, 11 March 2020. Available at: https://www.who.int/dg/speeches/detail/who-director-general-sopening-remarks-at-the-media-briefing-on-covid-19---11-march-2020. Accessed on 25 April 2020.

2. Ministry of Health Singapore. Risk assessment raised to Dorscon orange 2020, 26 April 2020. Available at: https://www.moh.gov.sg/ news-highlights/details/risk-assessment-raised-to-dorscon-orange. Accessed on 26 April 2020.

3. Lim EC, Oh VM, Koh DR, Seet RC. The challenges of "continuing medical education" in a pandemic era. Ann Acad Med Singapore 2009;38:724-726.

4. Ministry of Health Singapore. Updates on COVID-19 (coronavirus disease 2019) local situation. Available at: www.moh.gov.sg/covid-19. Accessed on 26 August 2020

5. American College of Obstetricians and Gynecologists (ACOG). ACOG patient resource: Coronavirus (COVID-19), pregnancy, and breastfeeding: a message for patients. Available at: https:/www.acog. org/patient-resources/faqs/pregnancy/coronavirus-pregnancy-andbreastfeeding\#What\%20is\%20COVID19. Accessed on 24 May 2020.

6. Royal College of Obstetricians and Gynaecologists (RCOG). RCOG guidance: Coronavirus (COVID-19) infection and pregnancy. Available at: https://www.rcog.org.uk/coronavirus-pregnancy. Accessed on 24 July 2020.

7. Dong L, Tian J, He S, Zhu C, Wang J, Liu C, et al. Possible vertical transmission of SARS-CoV-2 from an infected mother to her newborn. JAMA 2020;323:1846-48.

8. Zeng H, Xu C, Fan J, Tang Y, Deng Q, Zhang W, et al. Antibodies in infants born to mothers with COVID-19 pneumonia. JAMA 2020;323:1848-49.

9. Chen H, Guo J, Wang C, Luo F, Yu X, Zhang W, et al. Clinical characteristics and intrauterine vertical transmission potential 
of COVID-19 infection in nine pregnant women: a retrospective review of medical records. Lancet 2020;395:809-815.

10. Chen Y, Peng H, Wang L, Zhao Y, Zeng L, Gao H, et al. Infants born to mothers with a new coronavirus (COVID-19). Front Pediatr 2020;8:104.

11. Li N, Han L, Peng M, Lv Y, Ouyang Y, Liu K, et al. Maternal and neonatal outcomes of pregnant women with COVID-19 pneumonia: a case-control study. Clin Infect Dis 2020; doi: 10.1093/cid/ciaa352.

12. Zhu H, Wang L, Fang C, Peng S, Zhang L, Chang G, et al. Clinical analysis of 10 neonates born to mothers with 2019-nCoV pneumonia. Transl Pediatr 2020;9:51-60.

13. Wong SF, Chow KM, Leung TN, Ng WF, Ng TK, Shek CC, et al. Pregnancy and perinatal outcomes of women with severe acute respiratory syndrome. Am J Obstet Gynecol 2004;191:292-97.

14. Di Mascio D, Khalil A, Saccone G, Rizzo G, Buca D, Liberati M, et al. Outcome of coronavirus spectrum infections (SARS, MERS, COVID 1 -19) during pregnancy: a systematic review and metaanalysis. Am J Obstet Gynecol MFM 2020;2:100107.

15. Jamieson D, Honein MA, Rasmussen SA. H1N1 2009 influenza virus infection during pregnancy in the USA. Lancet 2009;374:451-58.

16. Siston AM, Rasmussen SA, Honein MA, Fry AM, Seib K, Callaghan WM, et al. Pandemic 2009 influenza A(H1N1) virus illness among pregnant women in the United States. JAMA 2010;303:1517-25.

17. Brooks SK, Webster RK, Smith LE, Woodland L, Wessely S, Greenberg $\mathrm{N}$, et al. The psychological impact of quarantine and how to reduce it: rapid review of the evidence. Lancet 2020;395:912-20

18. Wang C, Pan R, Wan X, Tan Y, Xu L, Ho CS, et al. Immediate psychological responses and associated factors during the initial stage of the 2019 coronavirus disease (COVID-19) epidemic among the general population in China. Int $\mathrm{J}$ Environ Res Public Health $2020 ; 17: 1729$
19. Shanafelt T, Ripp J, Trockel M. Understanding and addressing sources of anxiety among health care professionals during the COVID-19 pandemic. JAMA 2020; doi: 10.1001/jama.2020.5893.

20. Tan BYQ, Chew NWS, Lee GKH, Jing M, Goh Y, Yeo LLL, et al. Psychological impact of the COVID-19 pandemic on health care workers in Singapore. Ann Intern Med 2020;173:317-20.

21. Lai J, Ma S, Wang Y, Cai Z, Hu J, Wei N, et al. Factors associated with mental health outcomes among health care workers exposed to coronavirus disease 2019. JAMA Netw Open 2020;3:e203976.

22. Rajkumar RP. COVID-19 and mental health: A review of the existing literature. Asian J Psychiatr 2020;52:102066.

23. Lovibond SH, Lovibond PF. Manual for the depression anxiety stress scales. 2nd ed. Sydney: Psychology Foundation of Australia; 1995.

24. Xavier S, Bento E, Azevedo J, Marques M, Soares MJ, Freitas V, et al. Validation of the depression, anxiety and stress scale - DASS-21 in a community sample of portuguese women. European Psychiatry 2016;33:S283

25. Tran TD, Tran T, Fisher J. Validation of the depression anxiety stress scales (DASS) 21 as a screening instrument for depression and anxiety in a rural community-based cohort of northern Vietnamese women. BMC Psychiatry 2013;13:24.

26. Ministry of Health Singapore. Gov.sg whatsapp notification. Available at: https://mci.form.gov.sg/\#!/5e33fa3709f80b00113b6891. Accessed on 4 August 2020.

27. Rubin GJ, Harper S, Williams PD, Öström S, Bredbere S, Amlôt R, et al. How to support staff deploying on overseas humanitarian work: a qualitative analysis of responder views about the 2014/15 West African Ebola outbreak. Eur J Psychotraumatol 2016;7:30933.

28. Chua TE, Bautista DC, Tan KH, Yeo G, Chen H. Antenatal anxiety: prevalence and patterns in a routine obstetric population. Ann Acad Med Singapore 2018;47:405-12. 